ScIDice

\section{International Journal of Dentistry and Oral Science (IJDOS) \\ ISSN: 2377-8075}

\title{
Molar Incisor Hypomineralisation - A Review
}

Research Article

Dhanraj Ganapathy ${ }^{1 *}$, Harshinee Chandrasekhar ${ }^{2}$, Mahesh Ramakrishnan ${ }^{3}$

${ }^{1}$ Professor \& Head of Department, Department of Prosthodontics, Saveetha Dental College and Hospitals Saveetha Institute of Medical and Technical Sciences Saveetha University, Chennai-600077, India.

${ }^{2}$ Undergraduate student Saveetha Institute of Medical and Technical Sciences Saveetha University, Chennai-600077, India.

${ }^{3}$ Reader, Department of Pedodontics, Saveetha Dental College and Hospitals Saveetha University, Chennai-600077, India.

\section{Abstract}

Molar Incisor Hypomineralisation (MIH) is a type of enamel defect affecting the first molars and incisors in permanent dentition. It usually occurs in children under 10years. It is caused due to lack of mineralisation of Enamel. The enamel appears yellow, brown or white in colour. Children with MIH are more likely to experience tooth decay. Prevention is important at early developmental age to avoid the severity of the MIH. The review concentrates on the diagnosis, features, prevalence, and clinical management of molar incisor hypomineralization.

Keywords: Dentists; Molar; Hypomineralization.

\section{Introduction}

Hypomineralisation of systemic origin, presenting as demarcated, qualitative defects of enamel of one to four first permanent molars (FPMs) frequently associated with affected incisors. The occurrence of white to yellow-brown enamel opacities in the first permanent molars was first recognised in Sweden in the late 1970s. This phenomenon was subsequently coined molar incisor hypomineralization $(\mathrm{MIH})$ [7].

Tooth enamel is unique among mineralised tissues because of its high mineral content. Enamel is made up of highly organised, tightly packed crystallites that comprise $87 \%$ of its volume and $95 \%$ of its weight. Despite its hardness, tooth enamel can be destroyed fairly rapidly by dental caries. Additionally enamel is also afflicted by various structural defects which could be inherited or acquired [10].

These defects, characterized by discoloured opacities or a total absence of enamel, are observed to most commonly affect the first permanent molars (FPMs) with or without involvement of the permanent incisors and have been varyingly referred to in the literature as hypomineralized FPMs, idiopathic enamel hypomineralization, demineralized FPMs, non-fluoride hypomineralization, cheese molars, internal enamel hypoplasia, non-endemic mottling of enamel, opaque spots and enamel opacities [13].

Clinically, MIH can vary from mild demarcated opacities to severe structural loss. The defects can be white, yellow, or brown in colour, but they will show a clear demarcation between the affected and normal enamel (Weerheijm 2004).

\section{MIH's Clinical Management Is Challenging Due To:}

(i) The sensitivity and rapid development of dental caries in affected PFMs.

(ii) The limited co-operation of young children.

(iii) Difficulty in achieving anaesthesia; and

(iv) The repeated marginal breakdown of restorations [12].

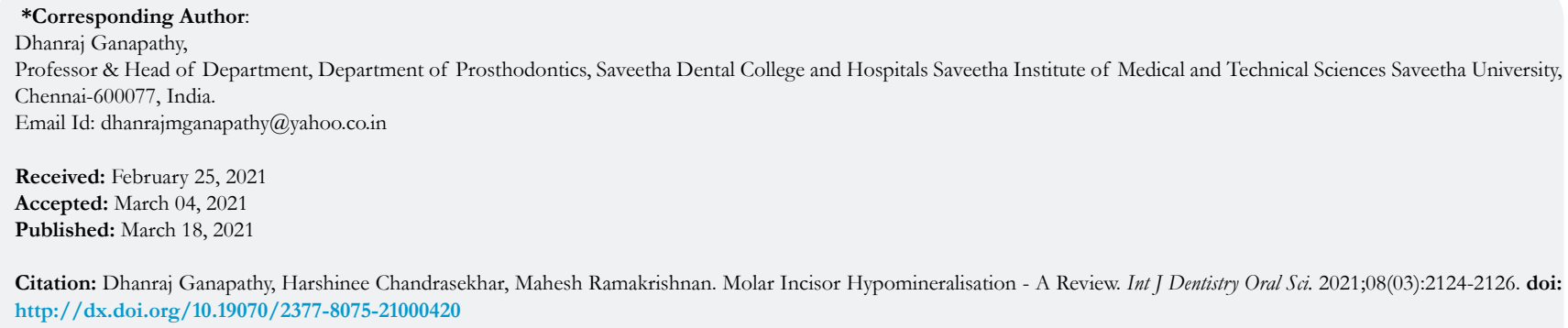

Copyright: Dhanraj Ganapathy 2021 . This is an open-access article distributed under the terms of the Creative Commons Attribution License, which permits unrestricted use, distribution and reproduction in any medium, provided the original author and source are credited. 
The purpose of this paper is to describe the diagnosis, prevalence, and clinical management in molar incisor hypomineralization.

\section{Etiology}

MIH was originally described as an idiopathic defect and a clear etiology for the condition is yet to be defined. Animal models suggested preceding events such as hypoxia, high fever, hypocalcaemia, exposure to antibiotics (amoxicillin), and dioxins as possible causes of MIH. When rats were exposed to a daily low dose of bisphenol A (BPA), an endocrine disrupting chemical, the exposed rats developed an enamel hypomineralization condition very similar to the human MIH.

BPA mainly targeted two genes (kallikrein-related peptidase 4, Klk4, and enamelin, Enam), which are responsible for enamel matrix protein secretion and enamel matrix degradation (to allow enamel mineral crystal growth), respectively. It was found that modulation of the expression of these genes led to enamel hypomineralization. BPA stimulates activity on ameloblast proliferation and gene transcription and provides evidence for a hormonal influence on amelogenesis, demonstrating that dental epithelial cells are estrogen targets [6].

Therefore, we propose that MIH is not an idiopathic but a genetic condition related to disturbances in the maturation stages of enamel, which in most instances are localized to first permanent molars and incisors. On occasion, second primary molars and permanent canines and premolars can also be affected. The involvement of additional teeth may be due to the influence of additional gene variants in any of more than 100 genes expressed during late enamel development.

\section{Signs and Symptoms}

Large demarcated opacities, whitish-cream or yellow-brown in colour.

May or May not be associated with post eruption enamel breakdown.

Hypersensitivity.

Difficult to anaesthetise.

Rapid caries progression.

The opacities are usually limited to the Incisal or cuspal one third of the crown, rarely involving the cervical one third, the subsurface enamel is soft and porous [5].

\section{Characteristics Of Affected Teeth}

$\mathrm{MIH}$ is a qualitative defective enamel classified as a hypomineralized type that follows the normal incremental lines of enamel formation, from cuspal to cementoenamel junction.

MIH enamel has substantially higher protein content than normal enamel, but a near normal level of residual amelogenins, this characteristic distinguishes MIH from hypomaturation, defects that contain high residual amelogenins such as Fluorosis $[3,8]$.

\section{Clinical Implications}

Clinically the affected teeth can be very sensitive to stimuli like a current of cold or warm air and mechanical provocations. The children with MIH molars or opacities on the incisors should be monitored carefully until all four permanent first molars have erupted. If molars show signs of opacities and post eruptive breakdown, a child should be seen every three months until the time when the permanent first molars have completely erupted [1].

\section{Management Of The MIH}

Ultrastructurally, opaque defects on anterior teeth usually extend through the full thickness of enamel, from the surface or subsurface down to the dentinoenameljunction (DEJ). For this reason, acid or pumice microabrasion techniques tend to produce little improvement when used alone. Direct composite veneering with or without preparation offers the most reliable medium term way of improving aesthetics of these teeth.

Hypomineralized enamel is very susceptible to decay and acid attack. An assessment of your child's diet should be carried out and appropriate recommendations made for dietary changes. In cases where tooth-brushing is difficult due to sensitive teeth, the following oral hygiene strategies may be helpful:-

Brush affected teeth gently with a fluoride containing desensitising toothpaste.

Apply tooth mousse TM Plus daily [9].

Thorough oral hygiene should be instituted; this could include a desensitising toothpaste. Remineralisation therapy should commence as soon as the defective surface is accessible, aiming to produce a hypomineralized surface layer and to desensitise the tooth. Remineralisation and desensitisation may be accomplished with casein phospho - peptide - amorphous calcium phosphate(CPPACP) oral care products. CPP-ACP care products enhance remineralisation by creating a state of supersaturation followed by deposition of calcium and phosphate ions at the enamel surface. While clinical protocols for CPP-ACP oral care products await development, anecdotal reports describe surface hardening and reduction in tooth sensitivity from daily home use [4].

Generally, the defects of the incisors are milder than those of the molars. Since masticatory forces on the opacities in incisors are absent, the enamel substance does not disintegrate after eruption. However, treatment is often required for aesthetic reasons. In such cases (and in the rare case of breakdown of the enamel), replacement with composite should be considered as first treatment option [2].

\section{Conclusion}

The prevalence of the MIH appears to be increasing and management of MIH affected children is common. As theetiology is multifactorial, children with poor general health should be considered more as they are at risk to develop MIH. Frequent monitoring of these patients is required as preventive measures can be instituted at the earliest. 
Hence research on etiology factors and preventive measures are required.

\section{References}

[1]. Allazzam SM, Alaki SM, El Meligy OA. Molar incisor hypomineralization, prevalence, and etiology. Int J Dent. 2014;2014:234508. Pubmed PMID: 24949012

[2]. Beentjes VE, Weerheijm KL, Groen HJ. Factors involved in the aetiology of molar-incisor hypomineralisation (MIH). European Journal of Paediatric Dentistry. 2002 Mar 1;3:9-13.

[3]. Farah R, Drummond B, Swain M, Williams S. Linking the clinical presentation of molar-incisor hypomineralisation to its mineral density. International journal of paediatric dentistry. 2010 Sep;20(5):353-60.

[4]. Fayle SA. Molar incisor hypomineralisation: restorative management. European Journal of Paediatric Dentistry. 2003 Sep 1;4:121-6.

[5]. Garg N, Jain AK, Saha S, Singh J. Essentiality of early diagnosis of molar incisor hypomineralization in children and review of its clinical presentation, etiology and management. Int J ClinPediatr Dent. 2012 Sep;5(3):1906. PubmedPMID: 25206166

[6]. Jedeon K, De la Dure-Molla M, Brookes SJ, Loiodice S, Marciano C,
Kirkham J, et al. Enamel defects reflect perinatal exposure to bisphenol A. Am J Pathol. 2013 Jul;183(1):108-18. PubmedPMID: 23764278.

[7]. Koch G, Hallonsten AL, Ludvigsson N, Hansson BO, Holst A, Ullbro C. Epidemiologic study of idiopathic enamel hypomineralization in permanent teeth of Swedish children. Community Dent Oral Epidemiol. 1987 Oct;15(5):279-85. Pubmed PMID: 3477361.

[8]. Mangum JE, Crombie FA, Kilpatrick N, Manton DJ, Hubbard MJ. Surface integrity governs the proteome of hypomineralized enamel. J Dent Res. 2010 Oct;89(10):1160-5. PubmedPMID: 20651090.

[9]. Oliver K, Messer LB, Manton DJ, Kan K, Ng F, Olsen C, et al. Distribution and severity of molar hypomineralisation: trial of a new severity index. Int J Paediatr Dent. 2014 Mar;24(2):131-51. PubmedPMID: 23701232.

[10]. Simmer JP, Hu JC. Dental enamel formation and its impact on clinical dentistry. Journal of dental education. 2001 Sep;65(9):896-905.

[11]. Weerheijm KL. Molar incisor hypomineralization (MIH): clinical presentation, aetiology and management. Dental update. 2004 Jan 2;31(1):9-12.

[12]. William V, Messer LB, Burrow MF. Molar incisor hypomineralization: review and recommendations for clinical management. Pediatr Dent. 2006 May-Jun;28(3):224-32.Pubmed PMID: 16805354.

[13]. Willmott NS, Bryan RA, Duggal MS. Molar-incisor-hypomineralisation: a literature review. Eur Arch Paediatr Dent. 2008 Dec;9(4):172-9. Pubmed PMID: 19054470. 